\title{
A MULTI-OBJECTIVE GENETIC ALGORITHMS APPROACH FOR MODELLING OF ORDER PICKING
}

\author{
Gajsek, B. ; Dukic, G. ${ }^{* *}$; Kovacic, M.***,**** \& Brezocnik, M. \\ ${ }^{*}$ University of Maribor, Faculty of Logistics, Mariborska 7, 3000 Celje, Slovenia \\ ** University of Zagreb, Faculty of Mechanical Engineering and Naval Architecture, \\ U1. Ivana Lučića 5, 10000 Zagreb, Croatia \\ *** Štore Steel d.o.o., Železarska 7, 3220 Štore, Slovenia \\ ${ }^{* * * *}$ University of Ljubljana, Faculty of Mechanical Engineering, Laboratory for Fluid Dynamics \\ and Thermodynamics, Aškerčeva 6, 1000 Ljubljana, Slovenia \\ University of Maribor, Faculty of Mechanical Engineering, Intelligent Manufacturing Systems \\ Laboratory, Smetanova 17, 2000 Maribor, Slovenia \\ E-Mail: brigita.gajsek@um.si,goran.dukic@fsb.hr,miha.kovacic@store-steel.si, \\ miran.brezocnik@um.si
}

\begin{abstract}
Because the proportion of working-age people in the EU is shrinking, it is necessary to help employers to be able to install various aids to maintain the health of employees, especially in very demanding manual jobs. Well-being is thus becoming just as important as cost reduction. One such area is manto-goods manual order picking. The paper proposes genetic algorithms (GA) to assist logistics managers in deciding about the most optimal pattern of stacking items in storage locations in storage racks. During the peak season, it makes sense to arrange items in terms of the minimum consumption of time when taking them manually out of the shelves and in periods of lower demand in terms of minimum chances of injury to employees and their low energy consumption. Based on experimental data, several models for predicting time, health risk, and energy consumption at order picking were developed by the GA. The results showed that GA is a powerful tool for resolving the storage assignment problems in terms of optimization according to individual criteria (time spent, risk of injury, or energy consumed) or searching for a common optimal solution.

(Received in August 2021, accepted in November 2021. This paper was with the authors 6 weeks for 1 revision.)
\end{abstract}

Key Words: Order Picking, Productivity, Energy Expenditure, Health Risk, Modelling and Optimization, Genetic Algorithm

\section{INTRODUCTION}

Order picking is the most expensive warehouse activity [1]. Much time is spent as employees use the list to continuously walk tens of kilometres along the shelves, retrieve items, and carry or transport them to the disposal sites to fulfil customer orders. In addition, the work is also strenuous. Shelves with items are placed from the floor surface to the upper limit of vertical reach for a lifting up to $175 \mathrm{~cm}$ [2], which requires stretching or bending at the retrieval. Low back pain (LBP) and injuries attributed to manual lifting activities lead to occupational health and safety issues. Occupations reporting the highest rates of LBP include nursing, transportation, construction, warehousing, and landscaping [3]. Whether LBP leads to disabling levels of workplace dysfunction depends on the individual, system-level, and workplace characteristics, not just on pain intensity [3]. In some countries, regulations and policies require employers to support workers with LBP to prevent long-term work disability, unemployment, or unnecessary absenteeism. In organizations with more proactive policies in return-to-work facilitation and job modification, workers experience fewer sick days and report more positive return-to-work outcomes $[4,5]$. The development and use of ways to avoid the risk of injury would result through a smaller number of days of absence from work and reduce costs in the warehouse over a more extended period. 
Van Gils et al. [6] divide managerial decisions regarding order picking into strategic, tactical, and operational. Their review and classification of recent order picking planning literature emphasize the importance of combining multiple tactical and operational planning problems in man-to-goods order picking systems. Among 61 papers, 54 papers use order picking time as a performance evaluation dimension, which helps managers assess the operations' performance and make consequential decisions. Problems were in $51 \%$ sold with simulations, $28 \%$ with mathematical programming, and $21 \%$ with analytical models. Simulations are primarily used to simulate combinations of order picking planning problems without analysing relations between them. Metaheuristics for solving large real-life mathematical programming problems are a popular approach [7]. Despite that, only a few integrated problems have been solved by metaheuristic algorithms [6]. Early use of genetic algorithm (GA) in order picking planning problems covers solving one order picking planning problem, such as minimizing travel distance in a conventional warehouse system [8]. Later, multiple GA method was used. Four such studies were found. In the first, a batch picking model is constructed that considers travel cost, earliness, and tardiness penalty to fulfil the current complex and quick-response-oriented environment [8]. In the second, GA was used to design storage assignment and order picking systems using a developed mathematical model and stochastic evolutionary optimization approach [9]. The third discusses the integrated order batching, sequencing and routing problem in warehouses using hybrid-coded GA, which is responsible for searching the near-optimal solutions of order batching and batch sequencing decisions by the hybrid-coded chromosome design and the evolutionary processes [10]. The fourth proposes novel tabu search algorithms integrated with a novel clustering algorithm to solve the order batching and picker routing problems. Recent research efforts have been put into a faster GA to form optimal batches and routes for the order picker. Authors still search for new approaches to combine different order picking planning problems and solve them simultaneously to provide superior material handling performance [11]. As it is presented, most of the research effort is invested in improving the performance of order picking through improved productivity, time, service, and costs. In doing so, GA is beneficial for solving combined order picking planning problems of operational nature, including batching, job assignment, and routing. To include the human factor and be able to protect workers' health, we need to extend order picking problem solving to the tactical level of decision-making also. Here, however, GAs have not yet been involved. Suppose at the operational level we are looking for the shortest route between the locations that need to be visited, then on a tactical level, thinking is more long-term focused. In that case, we want to be a little more tactful in determining the storage locations that will remain unchanged for a slightly more extended period, for example, a period of high demand. Simulations and practice showed that a specific item's storage location selection in a warehouse rack influences number of items collected per unit time, fatigue, and physical health of order pickers.

Consequently, the number of scientific contributions developing decision support models focusing on the assignment of items to storage locations is growing [12,13]. Storage assignments tactics that influence overall picking time and burden on workers are: (1) tactical classification of items at different heights in storage locations [14], (2) storing high-demand items in the area between a picker's waist and shoulders [15, 16], and (3) planning rest periods based on predicted energy expenditure [17]. The shortcoming of the mentioned approaches is in non-disclosed health risks for workers in the results of used methods [14]. So far, we have only reviewed the findings of the management-oriented research stream in which we observed a lack of interest in order pickers' well-being, which has been separately studied in the ergonomics literature [18]. Studies revealed that involvement in the manual order picking process poses a risk of developing musculoskeletal disorders [19,20]. An order picker 
intensely performs a varied set of movements and postures with the whole body. High frequency of repetitions, thus creating a risk of various musculoskeletal disorders [21]. The idea of the need to consider ergonomics or human factors issues into order picking planning models arose in 2015 [15]. Since then, the number of scientific papers combining both fields have been growing. Some multi-objective models, including time and health risk dimensions, are already proposed [18, 22-25]. The authors listed as opportunities for further research: (1) analyses of the impact of order profiles, especially the number of items (mass) to be picked per line of an order $[18,22,23]$, (2) disclosure of the frequency of workers' risk exposure to situations with medium or high risk for injuries like musculoskeletal disorders [24], and (3) inclusion of human factors besides focusing on time minimization [25].

Several literature reviews were done on order picking planning problems [6], order picker routing in warehouses [13], incorporating human factors in order picking planning models [15], and human factors in order picking [26]. The research opportunity is seen in searching for a solution to the order picking planning problem, where the number of situations at order picking from a warehouse rack poses a risk for musculoskeletal disorders is unknown. However, the order picking must remain optimal in terms of time, despite considering the human factor. We will try to solve this by linking the tactical assignment of items to the storage locations and the operational picking of items from the storage rack to identify risky situations in parallel. GA has not yet been used for this purpose, although it has proven to be an appropriate tool to solve order picking planning problems.

In this paper we proposed a GA approach to solve a tactical assignment problem in a small warehouse, where there is no need to quickly recalculate a large amount of data. The paper begins with an explanation of methods which is followed by modelling, results, and discussion.

\section{MATERIALS AND METHODS}

A warehouse consists of a single storage rack with nine horizontal shelves divided into nine storage spaces (Fig. 1). Nine different items, boxes in different volumes and masses, were stored on each shelf, randomly arranged along the shelf. Forty-five storage spaces have fixed and equal dimensions. Each box was positioned in the middle of the front view of the storage space.
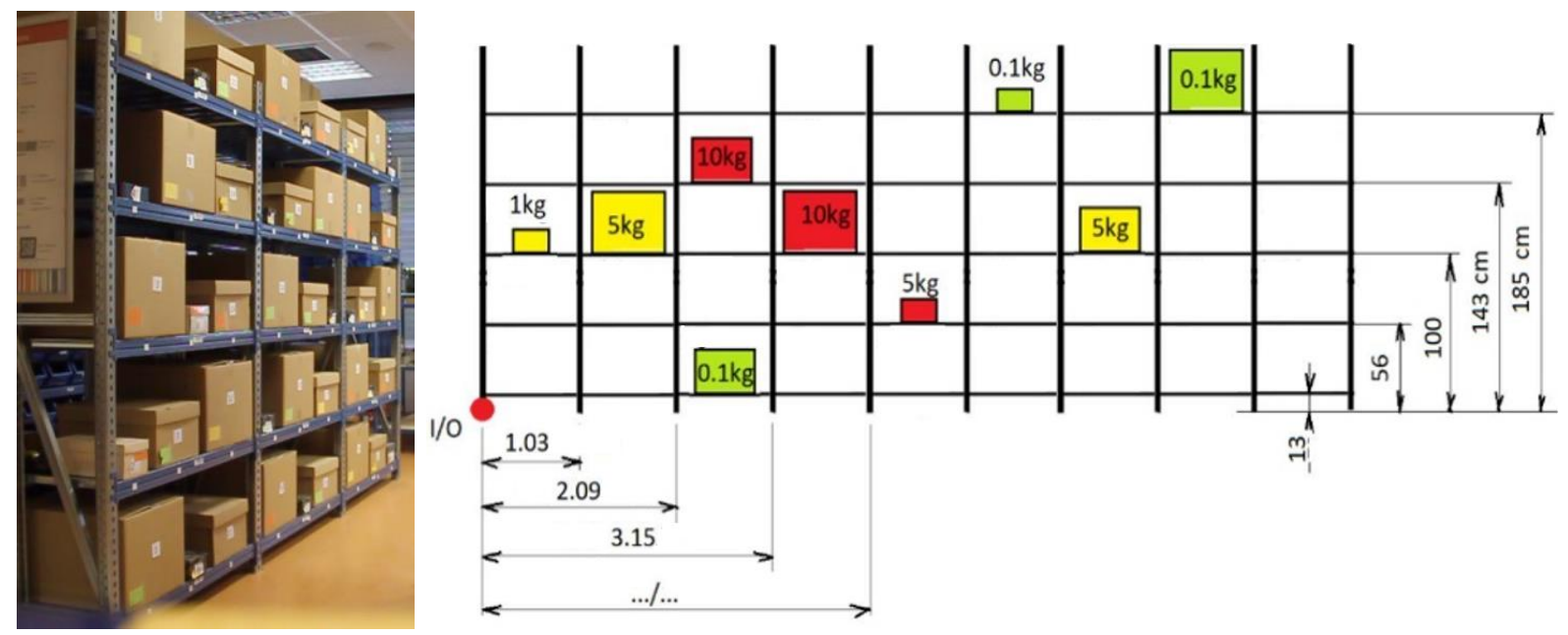

Figure 1: Storage rack with technical data.

Nine different items appear in the system. Their dimensions and masses are shown in Table I. Each item can be placed on five different heights from $13 \mathrm{~cm}$ to $185 \mathrm{~cm}$ above the 
ground (Fig. 1). From the theory, it is well known that picking items from different heights require different amounts of time. Times were measured experimentally [21].

Table I: Items' dimensions and masses.

\begin{tabular}{|c|c|c|c|c|c|c|c|c|c|}
\hline Short name & LVHM & LVMM & LVLM & MVHM & MVMM & MVLM & SVHM & SVMM & SVLM \\
\hline $\begin{array}{c}\text { Description } \\
\text { of naming }\end{array}$ & $\begin{array}{c}\text { Large } \\
\text { volume, } \\
\text { heavy } \\
\text { box }\end{array}$ & $\begin{array}{c}\text { Large } \\
\text { volume, } \\
\text { medium } \\
\text { heavy } \\
\text { box }\end{array}$ & $\begin{array}{c}\text { Large } \\
\text { volume, } \\
\text { light box }\end{array}$ & $\begin{array}{c}\text { Medium } \\
\text { volume, } \\
\text { heavy } \\
\text { box }\end{array}$ & $\begin{array}{c}\text { Medium } \\
\text { volume, } \\
\text { medium } \\
\text { heavy } \\
\text { box }\end{array}$ & $\begin{array}{c}\text { Medium } \\
\text { volume, } \\
\text { light box }\end{array}$ & $\begin{array}{c}\text { Small } \\
\text { volume, } \\
\text { heavy } \\
\text { box }\end{array}$ & $\begin{array}{c}\text { Small } \\
\text { volume, } \\
\text { medium } \\
\text { heavy } \\
\text { box }\end{array}$ & $\begin{array}{c}\text { Small } \\
\text { volume, } \\
\text { light box }\end{array}$ \\
\hline Dimensions & $10 \mathrm{~kg}$ & $5 \mathrm{~kg}$ & $0.1 \mathrm{~kg}$ & $10 \mathrm{~kg}$ & $5 \mathrm{~kg}$ & $0.1 \mathrm{~kg}$ & $5 \mathrm{~kg}$ & $1 \mathrm{~kg}$ & $0.1 \mathrm{~kg}$ \\
\hline Mass & \multicolumn{3}{|l|}{$31 \mathrm{~cm} \times 37 \mathrm{~cm} \times 45 \mathrm{~cm}$} & \multicolumn{2}{|c|}{$20 \mathrm{~cm} \times 30 \mathrm{~cm} \times 40 \mathrm{~cm}$} & $7 \mathrm{~cm} \times 11 \mathrm{~cm} \times 18 \mathrm{~cm}$ \\
\hline
\end{tabular}

The OWAS method was used to determine health risk for specific box on specific storage space, considering the frequency of its picking from the rack. The method is described in more detail in [27], as well as the method of determining the code marks. Fig. 2 presents observation of different work postures during the order picking process.
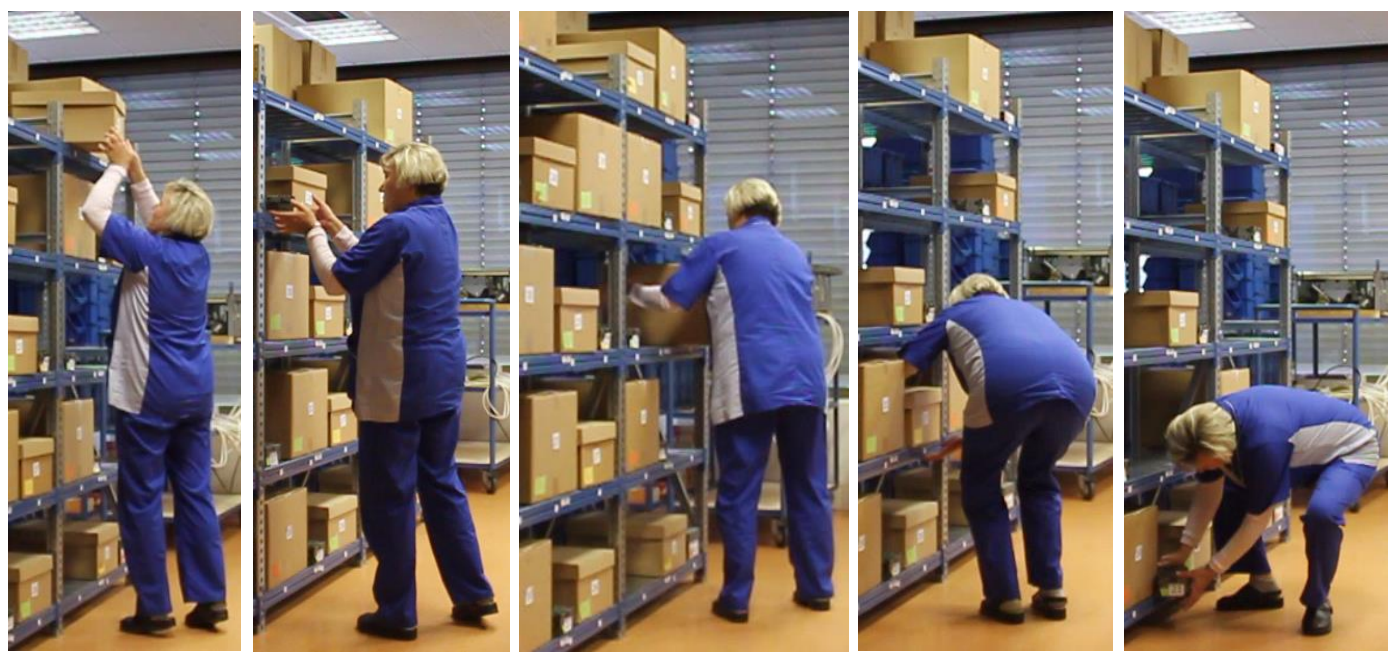

Figure 2: Different work postures during the order picking process.

For performing different movements, in our case picking, lifting, lowering, and walking, worker consumes energy. Energy expenditure was calculated for each item on each possible height according to [28]. All needed data for modelling are presented in Table II.

\section{MODELLING}

In this paper, the genetic algorithm (GA) approach was used as a search strategy. The GA is the evolutionary algorithms search heuristic which mimics the Darwin's theory of biological evolution of living beings [20]. The GA and other population-based algorithms are general solving techniques that can be used for solving different one- and multi-objective problems in the engineering field as-well as in many other related areas (see for example [29-35]).

The organisms (i.e., order picking schedule) consist of genes (i.e., storage spaces). Each gene contains the data on location of individual storage space. Each storage space corresponds to a box from the list of available boxes, which always remains the same. This practically means that for each box from the same list, different locations/storage spaces are available. The proposed system is realized within the AutoCAD system using the AutoLISP programming language. 
Gajsek, Dukic, Kovacic, Brezocnik: A Multi-Objective Genetic Algorithms Approach for ...

Table II: Order picking times, energy expenditures, OWAS codes and frequencies for items on different heights in storage rack.

\begin{tabular}{|c|c|c|c|c|c|c|c|c|c|}
\hline Number & $\begin{array}{c}\text { Volume } \\
{\left[\mathrm{m}^{3}\right]}\end{array}$ & $\begin{array}{c}\text { Mass } \\
{[\mathrm{kg}]}\end{array}$ & $\begin{array}{c}\text { Shelf } \\
\text { height } \\
{[\mathrm{cm}]}\end{array}$ & $\begin{array}{c}\text { Picking } \\
\text { time } \\
{[\mathrm{s}]}\end{array}$ & $\begin{array}{c}\text { Energy for } \\
\text { picking and } \\
\text { walking } \\
{[\mathrm{kcal}]}\end{array}$ & $\begin{array}{c}\text { OWAS } \\
\text { code - } \\
\text { Back }\end{array}$ & $\begin{array}{c}\text { OWAS } \\
\text { code - } \\
\text { Arms }\end{array}$ & $\begin{array}{c}\text { OWAS } \\
\text { code - } \\
\text { Legs }\end{array}$ & Frequency \\
\hline 1 & 0.051615 & 5 & 13 & 3.77 & 0.7269 & 2 & 2 & 4 & 0.0059801 \\
\hline 2 & 0.051615 & 5 & 56 & 3.57 & 0.3405 & 2 & 2 & 2 & 0.0133005 \\
\hline 3 & 0.051615 & 5 & 100 & 3.13 & 0.2203 & 1 & 1 & 2 & 0.0108871 \\
\hline 4 & 0.051615 & 5 & 143 & 3.3 & 0.328 & 1 & 3 & 2 & 0.0213439 \\
\hline 5 & 0.051615 & 5 & 185 & 4.54 & 0.4114 & 2 & 3 & 2 & 0.0818182 \\
\hline 6 & 0.051615 & 10 & 13 & 4.37 & 0.8035 & 2 & 2 & 4 & 0.0593407 \\
\hline 7 & 0.051615 & 10 & 56 & 3.85 & 0.4331 & 2 & 2 & 2 & 0.0039187 \\
\hline 8 & 0.051615 & 10 & 100 & 3.99 & 0.3114 & 1 & 1 & 2 & 0.0284211 \\
\hline 9 & 0.051615 & 10 & 143 & 4.15 & 0.4797 & 1 & 3 & 2 & 0.0352941 \\
\hline 10 & 0.051615 & 10 & 185 & 5.57 & 0.6133 & 2 & 3 & 2 & 0.12 \\
\hline 11 & 0.051615 & 0.1 & 13 & 2.71 & 0.6505 & 2 & 2 & 4 & 0.0047872 \\
\hline 12 & 0.051615 & 0.1 & 56 & 2.62 & 0.2481 & 2 & 2 & 2 & 0.0315789 \\
\hline 13 & 0.051615 & 0.1 & 100 & 2.71 & 0.1294 & 1 & 1 & 2 & 0.0065854 \\
\hline 14 & 0.051615 & 0.1 & 143 & 2.8 & 0.1766 & 1 & 3 & 2 & 0.0040724 \\
\hline 15 & 0.051615 & 0.1 & 185 & 3.04 & 0.2098 & 2 & 3 & 2 & 0.0081081 \\
\hline 16 & 0.024 & 5 & 13 & 3.7 & 0.7243 & 2 & 2 & 4 & 0.0062718 \\
\hline 17 & 0.024 & 5 & 56 & 3.44 & 0.3432 & 2 & 2 & 2 & 0.0116129 \\
\hline 18 & 0.024 & 5 & 100 & 3.21 & 0.2256 & 1 & 1 & 2 & 0.0102273 \\
\hline 19 & 0.024 & 5 & 143 & 3.81 & 0.3347 & 1 & 3 & 2 & 0.0057082 \\
\hline 20 & 0.024 & 5 & 185 & 4.23 & 0.4161 & 2 & 3 & 2 & 0.0054545 \\
\hline 21 & 0.024 & 10 & 13 & 4.03 & 0.7996 & 2 & 2 & 4 & 0.0257143 \\
\hline 22 & 0.024 & 10 & 56 & 3.7 & 0.437 & 2 & 2 & 2 & 0.0045918 \\
\hline 23 & 0.024 & 10 & 100 & 3.77 & 0.3191 & 1 & 1 & 2 & 0.045 \\
\hline 24 & 0.024 & 10 & 143 & 4.16 & 0.4895 & 1 & 3 & 2 & 0.0042353 \\
\hline 25 & 0.024 & 10 & 185 & 5.39 & 0.6202 & 2 & 3 & 2 & 0.0049954 \\
\hline 26 & 0.024 & 0.1 & 13 & 2.5 & 0.6491 & 2 & 2 & 4 & 0.0692308 \\
\hline 27 & 0.024 & 0.1 & 56 & 2.3 & 0.2496 & 2 & 2 & 2 & 0.0514286 \\
\hline 28 & 0.024 & 0.1 & 100 & 2.26 & 0.1323 & 1 & 1 & 2 & 0.0397059 \\
\hline 29 & 0.024 & 0.1 & 143 & 2.19 & 0.1802 & 1 & 3 & 2 & 0.0981818 \\
\hline 30 & 0.024 & 0.1 & 185 & 2.73 & 0.2124 & 2 & 3 & 2 & 0.0072874 \\
\hline 31 & 0.001386 & 1 & 13 & 2.21 & 0.6632 & 2 & 2 & 4 & 0.0142857 \\
\hline 32 & 0.001386 & 1 & 56 & 1.95 & 0.2698 & 2 & 2 & 2 & 0.0096257 \\
\hline 33 & 0.001386 & 1 & 100 & 2 & 0.1558 & 1 & 1 & 2 & 0.0090756 \\
\hline 34 & 0.001386 & 1 & 143 & 2.15 & 0.2159 & 1 & 3 & 2 & 0.0085714 \\
\hline 35 & 0.001386 & 1 & 185 & 2.61 & 0.26 & 2 & 3 & 2 & 0.0153846 \\
\hline 36 & 0.001386 & 5 & 13 & 2.91 & 0.723 & 2 & 2 & 4 & 0.0195652 \\
\hline 37 & 0.001386 & 5 & 56 & 2.73 & 0.3459 & 2 & 2 & 2 & 0.0166154 \\
\hline 38 & 0.001386 & 5 & 100 & 2.78 & 0.2336 & 1 & 1 & 2 & 0.0124138 \\
\hline 39 & 0.001386 & 5 & 143 & 3.14 & 0.3426 & 1 & 3 & 2 & 0.0233766 \\
\hline 40 & 0.001386 & 5 & 185 & 3.45 & 0.4275 & 2 & 3 & 2 & 0.018 \\
\hline 41 & 0.001386 & 0.1 & 13 & 1.95 & 0.6484 & 2 & 2 & 4 & 0.0069231 \\
\hline 42 & 0.001386 & 0.1 & 56 & 1.74 & 0.251 & 2 & 2 & 2 & 0.0076814 \\
\hline 43 & 0.001386 & 0.1 & 100 & 1.71 & 0.1366 & 1 & 1 & 2 & 0.0037736 \\
\hline 44 & 0.001386 & 0.1 & 143 & 1.79 & 0.1845 & 1 & 3 & 2 & 0.0044082 \\
\hline 45 & 0.001386 & 0.1 & 185 & 2 & 0.2185 & 2 & 3 & 2 & 0.0052174 \\
\hline
\end{tabular}


For altering organisms, the genetic operations of crossover (one-point crossover) and permutation were used. The permutation swaps the locations/storage spaces of randomly selected two individuals (i.e., order picking schedule). The reproduction operation which does not change the organisms is also implemented. The following values for the evolutionary parameters were used: the population size of 500 organisms, the maximum number of generations 100 , the tournament selection with a tournament size of 7 , the crossover probability 0.7 , the probability of permutation 0.2 , and the probability of reproduction 0.1 .

The evaluation function $F$ can be defined as:

$$
F=w_{1} \cdot \text { time }-w_{2} \cdot \text { energy }-\left(1-w_{1}-w_{2}\right) \cdot \text { risk },
$$

where $w_{1}$ and $w_{2}$ are corresponding weights (from 0 to 1 ) which can be adjusted. In the paper several combinations of weights were used. The order picking time (time) can be calculated using following equation:

$$
\text { time }=\frac{\sum_{i=1}^{n}\left(2 \cdot h_{-} \text {distance }_{i} \cdot w_{-} \text {speed }_{+} \text {pick_time }_{i}\right)}{n \cdot \min \left(2 \cdot h_{\text {distance }_{j}} \cdot w_{\text {speed }}+\text { pick_time }_{j}\right) ; j=1 \ldots . .},
$$

where $h \_$distance is the horizontal distance from the starting point $I / O$ (Fig. 1 ) to the individual storage space $i, w_{-}$speed is walking speed $(1 \mathrm{~m} / \mathrm{s})$, pick_time is picking time for individual storage space $i$ and the corresponding box from Table II and $n$ is a number of storage spaces.

The energy for picking and walking (energy) is the summation of all needed energies (energy $y_{i}$ ) for picking and walking used for individual storage space $i$ and corresponding box from Table II divided by several storage spaces $n$ and minimal picking and walking energy out of all order picking movements:

$$
\text { energy }=\frac{\sum_{i=1}^{n}\left(\text { energy }_{i}\right)}{n \cdot \min \left(\text { energy }_{j}\right) ; j=1 \ldots n} .
$$

The health risk (risk) is calculated using following equation:

$$
\text { risk }=\frac{\frac{\text { back }+ \text { arms }+ \text { legs }}{3}}{0.5}
$$

where back, arms and legs are OWAS codes for back, arms and legs for individual storage space $i$ and corresponding box from Table II, respectively. Please note that the OWAS lowest value was defined as 0.5 .

\section{RESULTS AND DISCUSION}

\subsection{Validation through results}

Given that the purpose of the study was to determine whether GA can be used for a multiobjective approach to order picking modelling for decision-making at the tactical level, we used the results of previous research [18] to validate the model, which investigated the relationship between time consumption and energy consumption picking along one storage rack. Mentioned previous research revealed the maximum difference between optimal solutions is approximately $2 \%$ from time spent perspective and $2.5 \%$ from energy consumption perspective. In their case, the order fulfilment time in employing the energybased storage assignment was $2 \%$ higher than the total time that results if the time-based assignment was used $[18,21]$. Comparable results from the previous study contributed to the validation of our model.

The behaviour of individual observed dimensions (time spent, energy consumption, risk for MSD) at different weights of the importance of each dimension is shown in Fig. 3. 


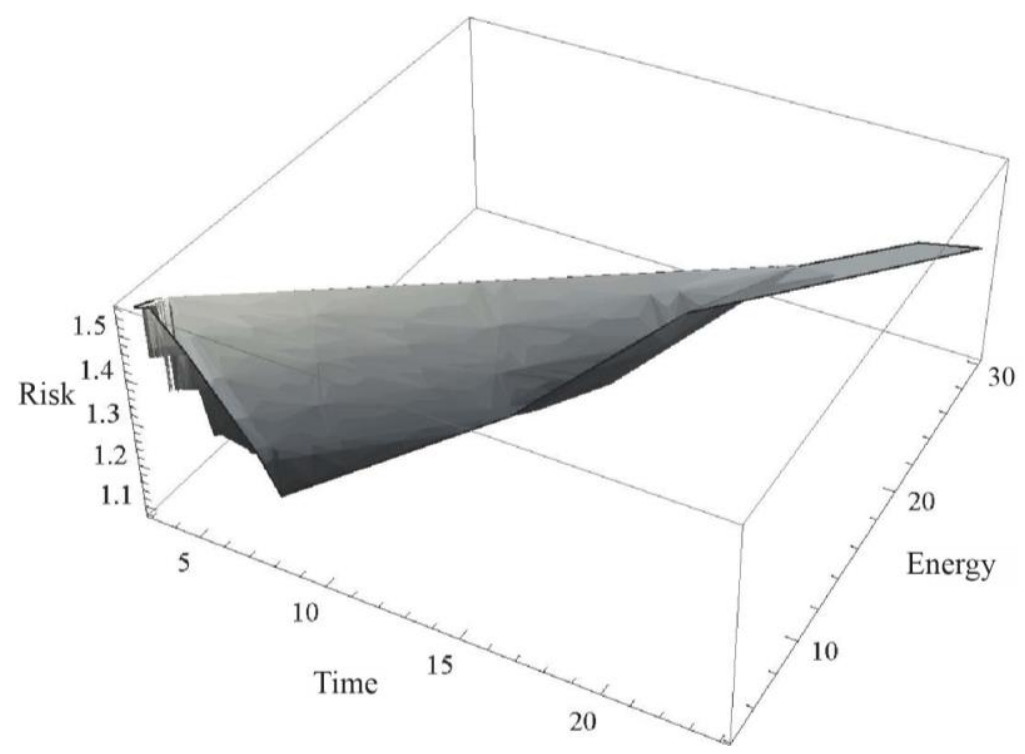

Figure 3: Correlation between spent time, energy expended, and the risk of developing MSDs during the order picking process.

\subsection{Functionality of the developed tool}

Given that the number of placements of items with a high risk of MSD in the optimal scenario after (1) time spent or (2) energy consumption can vary greatly, it is important to visualize the specific classification of items in the shelf. Investigations of the results show that if we choose an assignment that will require either (1) a longer picking time or (2) lower energy consumption, it does not mean that no item in the assignment will be placed in a place that poses a risk of MSD. The trend in the number of high-risk cases is not proportional to the trend of time spent values or the trend of energy consumed values.

Figs. 4 to 6 show visualizations of assignments of items to storage locations in the storage rack. The allocations were created according to three different selection criteria. Fig. 4 presents graphical representation of allocation of items where the lowest risk is the selection criterion.

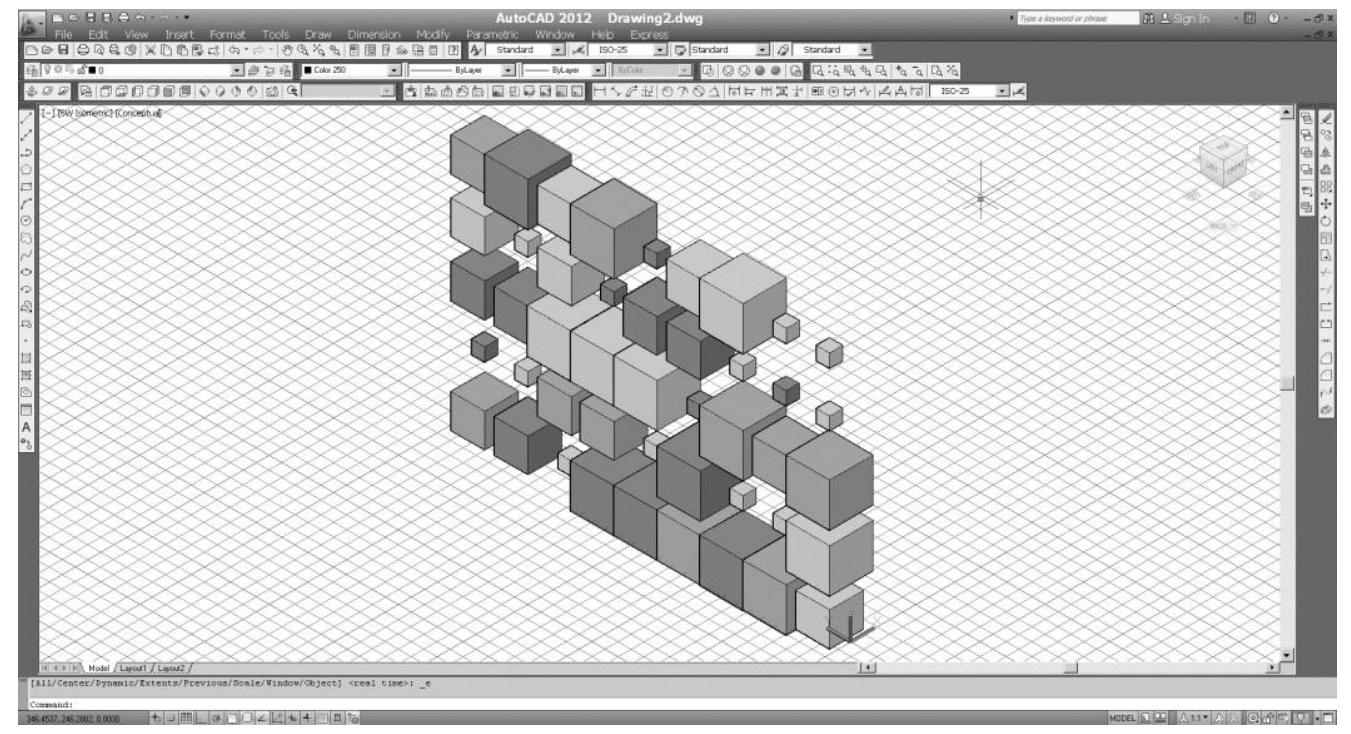

Figure 4: Graphical representation of result where the lowest risk is the selection criterion.

The tool developed in AutoCAD presents the proposal to the decision maker in a way that visualizes different sizes of items. The decision-maker has the option of assigning a specific 
colour to each individual item or to some of them. For example, a very heavy and at the same time very frequently picked item that has OWAS code greater than 1 at lower and higher positions in the rack could be coloured in red. The colour red on the screen means risk and special attention when making decisions.

Fig. 5 presents a graphical representation of allocation of items where the lowest energy consumption is the selection criterion. We proved experimentally (Table II) that picking heavier items from higher and lower shelves at the far part of the warehouse rack requires more energy consumption than picking the same item from the belly height area in an upright posture (golden zone) at the entrance to the warehouse rack, namely at the beginning of the rack.

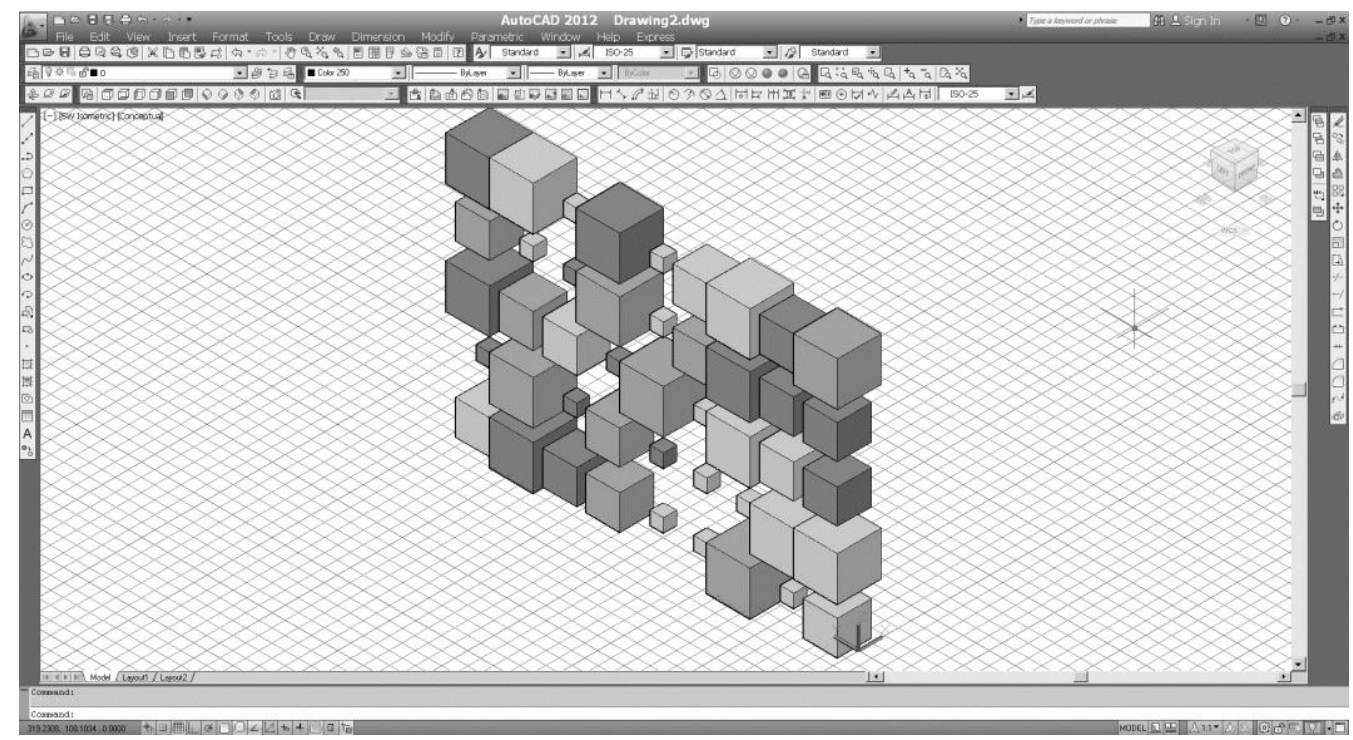

Figure 5: Graphical representation of result where the lowest energy consumption is the selection criterion.

Fig. 6 presents graphical representation of allocation of items where the lowest time spent is the selection criterion.

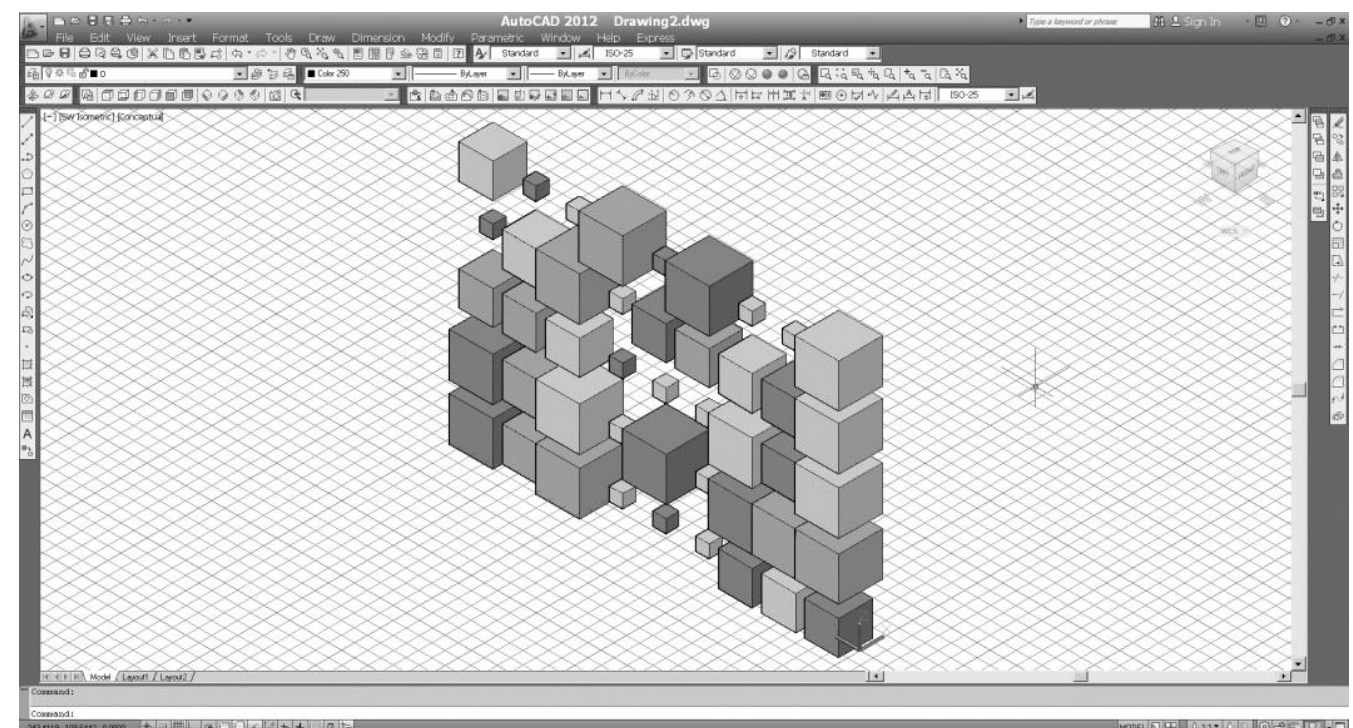

Figure 6: Graphical representation of result where the lowest time consumption is the selection criterion. 


\section{CONCLUSIONS}

This paper proposes the genetic algorithms approach to solve a tactical assignment problem in a small warehouse, where there is no need to quickly recalculate a large amount of data. We have also developed a tool for visualizing the specific assignment of the items to storage locations, according to the weights defined by the current situation. During the peak season, it is important to minimize time consumption, and in times of reduced demand, to relieve the burden on people and prevent the occurrence of MSD in the long run. In this way, with the added functionality of the possibility of colouring important items to the decision maker, the decision maker can try to further personalize the assignment scenario.

Our conclusions can be summarized as follows: (1) genetic algorithm approach can be added to the list of tools usable for multi-objective approach to order picking modelling, (2) the importance of each decision dimension (time spent, energy expenditure, risk for MSD occurrence) can be easily changed through weights, and (3) adding a tool to visualize solution empowers the decision-maker in terms of visualizing the notion of an individual assignment of the items to storage locations and the ability to mark important / critical items to the decision-maker by colouring them.

The model includes two important parameters for decision-makers (time spent and energy consumption) and also risk for MSD occurrence, which has not yet been done using genetic algorithm approach. Further research based on evolutionary analysis will explore more precisely mutual dependence of time spent, energy consumption and exclusively risk for MSD occurrence.

\section{REFERENCES}

[1] Marchet, G.; Melacini, M.; Perotti, S. (2015). Investigating order picking system adoption: a case-study-based approach, International Journal of Logistics Research and Applications, Vol. 18, No. 1, 82-98, doi:10.1080/13675567.2014.945400

[2] Waters, T. R.; Putz-Anderson, V.; Garg, A. (1994). Applications Manual for the Revised NIOSH Lifting Equation, U.S. Department of Health and Human Services, Centers for Disease Control and Prevention, National Institute for Occupational Safety and Health (NIOSH), DHHS (NIOSH) Publication No. 94-110 (Revised September 2021), Cincinnati, doi:10.26616/ NIOSHPUB94110revised092021

[3] Luckhaupt, S. E.; Dahlhamer, J. M.; Gonzales, G. T.; Lu, M.-L.; Groenewold, M.; Sweeney, M. H.; Ward, B. W. (2019). Prevalence, recognition of work-relatedness, and effect on work of low back pain among U.S. workers, Annals of Internal Medicine, Vol. 171, No. 4, 301-304, doi:10.7326/M18-3602

[4] Cullen, K. L.; Irvin, E.; Collie, A.; Clay, F.; Gensby, U.; Jennings, P. A.; Hogg-Johnson, S.; Kristman, V.; Laberge, M.; McKenzie, D.; Newnam, S.; Palagyi, A.; Ruseckaite, R.; Sheppard, D. M.; Shourie, S.; Steenstra, I.; van Eerd, D.; Amick III, B. C. (2018). Effectiveness of workplace interventions in return-to-work for musculoskeletal, pain-related, and mental health conditions: an update of the evidence and messages for practitioners, Journal of Occupational Rehabilitation, Vol. 28, No. 1, 1-15, doi:10.1007/s10926-016-9690-x

[5] Williams-Whitt, K.; Bültmann, U.; Amick III, B.; Munir, F.; Tveito, T. H.; Anema, J. R. (2016). Workplace interventions to prevent disability from both the scientific and practice perspectives: a comparison of scientific literature, grey literature, and stakeholder observations, Journal of Occupational Rehabilitation, Vol. 26, No. 4, 417-433, doi:10.1007/s10926-016-9664-Z

[6] Van Gils, T.; Ramaekers, K.; Caris, A.; de Koster, R. B. M. (2018). Designing efficient order picking systems by combining planning problems: state-of-the-art classification and review, European Journal of Operational Research, Vol. 267, No. 1, 1-15, doi:10.1016/ j.ejor.2017.09.002 
[7] Sörensen, K.; Glover, F. W. (2013). Metaheuristics, Gass, S. I.; Fu, M. C. (Eds.), Encyclopedia of Operations Research and Management Science, 960-970, Springer, Boston, doi:10.1007/978-14419-1153-7 1167

[8] Hsu, C.-M.; Chen, K.-Y.; Chen, M.-C. (2005). Batching orders in warehouses by minimizing travel distance with genetic algorithms, Computers in Industry, Vol. 56, No. 2, 169-178, doi:10.1016/j.compind.2004.06.001

[9] Ene, S.; Öztürk, N. (2012). Storage location assignment and order picking optimization in the automotive industry, The International Journal of Advanced Manufacturing Technology, Vol. 60, No. 5-8, 787-797, doi:10.1007/s00170-011-3593-y

[10] Chen, T.-L.; Cheng, C.-Y.; Chen, Y.-Y.; Chan, L.-K. (2015). An efficient hybrid algorithm for integrated order batching, sequencing and routing problem, International Journal of Production Economics, Vol. 159, 158-167, doi:10.1016/j.ijpe.2014.09.029

[11] Kulak, O.; Sahin, Y.; Taner, M. E. (2012). Joint order batching and picker routing in single and multiple-cross-aisle warehouses using cluster-based tabu search algorithms, Flexible Services and Manufacturing Journal, Vol. 24, No. 1, 52-80, doi:10.1007/s10696-011-9101-8

[12] De Koster, R.; Le-Duc, T.; Roodbergen, K. J. (2007). Design and control of warehouse order picking: a literature review, European Journal of Operational Research, Vol. 182, No. 2, 481501, doi:10.1016/j.ejor.2006.07.009

[13] Masae, M.; Glock, C. H.; Grosse, E. H. (2020). Order picker routing in warehouses: a systematic literature review, International Journal of Production Economics, Vol. 224, Paper 107564, 22 pages, doi:10.1016/j.ijpe.2019.107564

[14] Finnsgård, C.; Wänström, C.; Medbo, L.; Neumann, W. P. (2011). Impact of materials exposure on assembly workstation performance, International Journal of Production Research, Vol. 49, No. 24, 7253-7274, doi: $10.1080 / 00207543.2010 .503202$

[15] Grosse, E. H.; Glock, C. H.; Jaber, M. Y.; Neumann, P. W. (2015). Incorporating human factors in order picking planning models: framework and research opportunities, International Journal of Production Research, Vol. 53, No. 3, 695-717, doi:10.1080/00207543.2014.919424

[16] Petersen, C. G.; Siu, C.; Heiser, D. R. (2005). Improving order picking performance utilizing slotting and golden zone storage, International Journal of Operations \& Production Management, Vol. 25, No. 10, 997-1012, doi:10.1108/01443570510619491

[17] Calzavara, M.; Persona, A.; Sgarbossa, F.; Visentin, V. (2019). A model for rest allowance estimation to improve tasks assignment to operators, International Journal of Production Research, Vol. 57, No. 3, 948-962, doi:10.1080/00207543.2018.1497816

[18] Battini, D.; Glock, C. H.; Grosse, E. H.; Persona, A.; Sgarbossa, F. (2016). Human energy expenditure in order picking storage assignment: a bi-objective method, Computers \& Industrial Engineering, Vol. 94, 147-157, doi:10.1016/j.cie.2016.01.020

[19] Kadefors, R.; Forsman, M. (2000). Ergonomic evaluation of complex work: a participative approach employing video-computer interaction, exemplified in a study of order picking, International Journal of Industrial Ergonomics, Vol. 25, No. 4, 435-445, doi:10.1016/S01698141(99)00042-6

[20] Lavender, S. A.; Marras, W. S.; Ferguson, S. A.; Splittstoesser, R. E.; Yang, G. (2012). Developing physical exposure-based back injury risk models applicable to manual handling jobs in distribution centers, Journal of Occupational and Environmental Hygiene, Vol. 9, No. 7, 450459, doi:10.1080/15459624.2012.688464

[21] Gajšek, B.; Šinko, S.; Kramberger, T.; Butlewski, M.; Özceylan, E.; Đukić, G. (2021). Towards productive and ergonomic order picking: multi-objective modeling approach, Applied Sciences, Vol. 11, No. 9, Paper 4179, 27 pages, doi:10.3390/app11094179

[22] Harari, Y.; Riemer, R.; Bechar, A. (2018). Factors determining workers' pace while conducting continuous sequential lifting, carrying, and lowering tasks, Applied Ergonomics, Vol. 67, 61-70, doi:10.1016/j.apergo.2017.09.003

[23] Konz, S.; Rode, V. (1972). The control effect of small weights on hand-arm movements in the horizontal plane, A II E Transactions, Vol. 4, No. 3, 228-233, doi:10.1080/05695557208974854

[24] Larco, J. A.; de Koster, R.; Roodbergen, K. J.; Dul, J. (2017). Managing warehouse efficiency and worker discomfort through enhanced storage assignment decisions, International Journal of Production Research, Vol. 55, No. 21, 6407-6422, doi:10.1080/00207543.2016.1165880 
[25] Otto, A.; Boysen, N.; Scholl, A.; Walter, R. (2017). Ergonomic workplace design in the fast pick area, OR Spectrum, Vol. 39, No. 4, 945-975, doi:10.1007/s00291-017-0479-x

[26] Grosse, E. H.; Glock, C. H.; Neumann, W. P. (2017). Human factors in order picking: a content analysis of the literature, International Journal of Production Research, Vol. 55, No. 5, 12601276, doi: $10.1080 / 00207543.2016 .1186296$

[27] Grzybowska, K. (2010). An OWAS-based analysis of storekeeper workloads, Logistics and Transport, Vol. 10, No. 1, 57-63

[28] Garg, A.; Chaffin, D. B.; Herrin, G. D. (1978). Prediction of metabolic rates for manual materials handling jobs, American Industrial Hygiene Association Journal, Vol. 39, No. 8, 661-674, doi: $10.1080 / 0002889778507831$

[29] Ojstersek, R.; Tang, M.; Buchmeister, B. (2020). Due date optimization in multi-objective scheduling of flexible job shop production, Advances in Production Engineering \& Management, Vol. 15, No. 4, 481-492, doi:10.14743/apem2020.4.380

[30] Shi, D. L.; Zhang, B. B.; Li, Y. (2020). A multi-objective flexible job-shop scheduling model based on fuzzy theory and immune genetic algorithm, International Journal of Simulation Modelling, Vol. 19, No. 1, 123-133, doi:10.2507/IJSIMM19-1-CO1

[31] Arab, R.; Ghaderi, S. F.; Tavakkoli-Moghaddam, R. (2020). Two efficient meta-heuristic algorithms for the robust inventory routing problem with backhaul, Technical Gazette, Vol. 27, No. 3, 793-802, doi:10.17559/TV-20180814091028

[32] Janes, G.; Perinic, M.; Jurkovic, Z. (2017). Applying improved genetic algorithm for solving job shop scheduling problems, Technical Gazette, Vol. 24, No. 4, 1243-1247, doi:10.17559/TV20150527133957

[33] Istokovic, D.; Perinic, M.; Vlatkovic, M.; Brezocnik, M. (2020). Minimizing total production cost in a hybrid flow shop: a simulation-optimization approach, International Journal of Simulation Modelling, Vol. 19, No. 4, 559-570, doi:10.2507/IJSIMM19-4-525

[34] Amjad, M. K.; Butt, S. I.; Anjum, N.; Chaudhry, I. A.; Faping, Z.; Khan, M. (2020). A layered genetic algorithm with iterative diversification for optimization of flexible job shop scheduling problems, Advances in Production Engineering \& Management, Vol. 15, No. 4, 377-389, doi:10.14743/apem2020.4.372

[35] Quintero-Duran, M. J.; Candelo-Becerra, J. E.; Cabana-Jimenez, K. (2019). Distribution network reconfiguration with large number of switches solved by a modified binary bat algorithm and improved seed population, Technical Gazette, Vol. 26, No. 5, 1284-1291, doi:10.17559/TV$\underline{20180525204445}$ 